\title{
Effects of Terrorism Threat on Economic Preferences: The Role of Personality
}

\section{by Alina Velias and Philip J Corr}

\section{(cc) $\mathrm{BY}$}

This work is licensed under a Creative Commons Attribution 3.0 License.

\begin{abstract}
Certain threats, such as terrorism tend to have a low probability of affecting us directly, yet reminders of them (such as media news) are striking. Could individuals with particular personality traits find them distractive from the usual priorities in daily decision-making? This study explored the putative effects of media-driven terrorism threat, on two economic preferences (risk aversion and delay discounting) - using a sample reasonably closely representative of a modern Western city. Participants $(N=78)$ higher on impulsivity showed lower risk-seeking under terrorism threat. Discussed are directions for further research and the implications for media coverage of terrorist threat.
\end{abstract}

[Note: All supplementary materials referenced in this article may be downloaded from https://www.standrews.ac.uk/ cstpv/jtr/8 2/1305-3805-1-SP.pdf ]

\section{Introduction}

Terrorism has become a prominent feature of the modern world. While governments focus on preventing attacks and improving physical security, some researchers and policy-makers are concerned with the psychological 'ripple' effects on the public, suggesting that fear/anxiety, itself, may carry a cost and, as such, should be a major concern for governments (Sunstein, 2003). For many people, terrorism may be conceptualised as a dread risk which entails a high degree of uncertainty regarding the probability of threat, its time/location and mechanism of attack (Slovic, 2002) - where it is especially difficult to exercise personal control. These features of terrorism are made worse by the realisation that terrorists target places considered to be 'safe' and of everyday use.

Terrorism-related behaviour changes have been observed with regards to multiple risk-taking, impulsive behaviours and coping behaviours (see review by Ben-Zur \& Zeidner, 2009; for specific link of dread risk to car accidents, see Gigerenzer, 2006). Many of these changes were demonstrated to be affected, or even driven, by exposure to media (Ben-Zur, Gil, \& Shamshins, 2012). Individual differences in these effects have also been observed (Maguen, Papa, \& Litz, 2008). Although the literature is rich and varied, there is no consensus as to how far the threat reaches and the direction of effects on behaviour. Ben-Zur and Zeidner (2009) highlighted the tension between studies reporting an increase, on the one hand, in risky driving, substance abuse and raised consumption and, on the other hand, the substantial set of opposite or null effects - this may be due to the post-hoc nature of self-reported behaviours and conflation with extraneous variables, or, even, variation in the individual differences of participants in the different samples.

Controlled experimental studies offer insight into the ability of terrorism threat to evoke thoughts of one's own mortality (Mortality Salience, MS) within the Terror Management Theory (TMT) framework (Solomon, 


\section{Journal of Terrorism Research}

Greenberg, \& Pyszczynski, 2004). TMT states that we cope with the inevitability of death by celebrating life and affirming one's existence in the present. Consequently, thoughts of one's own death have been linked to such 'carpe diem' outcomes in economic decision-making as heightened risk-taking, reduced self-regulation, conspicuous consumption, and present-bias (reviewed in Burke, Martens, \& Faucher, 2010). Several studies in the TMT field have used specifically terrorism-based stimuli in experiments, but conclusions on risktaking and impulsive behaviours have, once again, been mixed. At the same time, an emerging literature on Uncertainty Management looks at changes in behaviour caused by uncertainty about how to behave and what to expect from the world (Van den Bos et al., 2005). Existing studies show that, in the domain of cultural beliefs, uncertainty has a different effect to mortality (Yavuz \& Van den Bos, 2009). Exploring whether a similar uncertainty component within the threat of terrorism would affect economic preferences appears important.

Individual differences under existential threat do not have an established link to economic preferences in the literature; however, there are reasons for believing such links may exist. Low socioeconomic status in childhood has been linked to higher risk-seeking and delay-impatience under salience of treacherous and life-threatening environments (Griskevicius, Tybur, Delton, \& Robertson, 2011). Self-esteem and locus of control over events in one's life has been shown to predict higher risk seeking (Burke et al., 2010). The lack of consensus in this literature points to the need for more studies to examine the relevance of personality traits in much more detail.

Although the specific links between personality and economic preferences have yet to be established (Almlund, Duckworth, Heckman, \& Kautz, 2011), there are some findings of relevance. Zuckerman and Kuhlman (2000) linked lower levels of impulsive sensation-seeking to lower risk-taking, appraisal of environment as being more threatening, and higher harm-avoidance. However, since most of the past studies have relied on the five-factor personality model, which includes impulsiveness as a subscale of neuroticism (Costa \& McCrae, 1992), it has proved difficult to disentangle the specific effects of impulsivity from those of neuroticism and harm-avoidance, which themselves have been shown to be associated with risk-averse decisions (Nicholson, Soane, Fenton-O’Creevy, \& Willman, 2005; Lauriola \& Levin, 2001). On a neuropsychological level, risk-taking tasks activate the insula, which is, in turn, linked to harm-avoidance and neuroticism (Paulus et al., 2003). Uncertainty, in turn, had been shown to provoke heightened neural response in same insula brain areas linked to harm-avoidance (Hirsh \& Inzlicht, 2008). In cancer patients, uncertainty about threat to life has been shown to manifest in present-focused consumption of 'possessions and experiences' (Pavia \& Mason, 2004).

The above leads us to suggest that certain dimensions of personality should respond to the uncertainty component of terrorism threat leading to more present-focused and harm-avoidant choices. We feel there is a need to test how individual variation in decision-making in reaction to terror-related and mortality-related stimuli relate to variation in major systems of approach and avoidance. To examine this issue, we adopted the theoretical framework afforded by the reinforcement sensitivity theory (RST) of personality (Gray \& McNaughton, 2000; McNaughton \& Corr, 2004; summarised in Corr, 2013) which provides measures of fundamental traits based on neurobehavioral systems underlying emotion and motivation. As detailed by Corr and Cooper (2016), RST contains three major systems: one positive, the Behavioural Approach System (BAS, related to approach motivation and the emotions of hopeful anticipation and reward reactivity); and two negative, the Fight-Flight-Freeze System (FFFS, related to avoidance/escape and the emotion of fear) and the Behavioural Inhibition System (BIS, related to the detection of goal-conflict and the emotion of anxiety). 


\section{Journal of Terrorism Research}

The advantage of using the RST personality scale is that it distinguishes between behaviour-inhibiting (BISrelated) anxiety and behaviour-expressive (BAS-related) impulsivity, as it also allows separation of (FFFSrelated) fear. We thus do not have a conflation of these separate factors with general neuroticism.

We made the following predictions.

1. We expected that individuals high on both impulsivity and anxiety would react most to the uncertainty component of terrorism, as assessed by behaviour reflecting greater harm-avoidance and present-focus - this would translate into choices of lower risks and more immediate rewards. However, recognizing that BIS-anxiety reflects not only reaction to a threat, but also behavioural inhibition until a goal-conflict is resolved, we anticipated that its effect may be less clear-cut than the one for impulsivity.

2. For mortality salience, which is associated with much higher certainty (we will all die eventually) and, therefore, more of a 'carpe diem' reminder to transcend death by celebrating life here and now, we expected high impulsivity and anxiety either not to dominate decision-making, or to lead to greater higher risk-taking and, likely, higher preference for immediate rewards.

3. To have a way of distinguishing effects on delay-impatience, we also suggested that individuals low on the Goal-Drive Persistence factor of BAS personality (responsible for focus on achievement of one's goals, and opposite to impulsive actions) would respond to the 'carpe diem' effect of mortality salience, increasing delay-impatience, but we predicted it would not change preferences under terrorism.

Most of the studies discussed above focused on people who experienced a proximate exposure to terrorism (Israeli citizens, New York citizens after 9/11, Turkey citizens). In contrast, we aimed to test a wider effect of terrorism, focusing on people exposed to it through news stories.

\section{Method[1]}

\section{Participants}

Data collection took place over August 2015. Participants $(\mathrm{N}=108)$ were recruited online to participate in the study which was described as an investigation of media and economic preferences. Fully completed surveys were entered in a raffle for $€ 20$ Amazon voucher. Some attempts $(n=22)$ were interrupted by a software issue. For the remaining 86 participants[2], mean age was 31 years ( $\mathrm{SD}=7.7)$; 54 were UK residents, $16 \mathrm{EU}$ residents, 12 resided in the rest of the world, 4 preferred not to declare.

The sample represented reasonably well the population of a modern Western city on dimensions of income, employment, religion, and sexual orientation - as compared to the demographics for London, Paris, New York or Berlin. There were 24 students, 46 full-time employed, 3 unemployed, 1 retired, 10 part-time employed, 2 non-declared; 39 were male, 41 female, 6 non-declared. Mean annual combined household

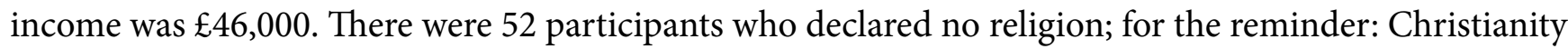
$=19$, Judaism $=2$, other religions $=2$, preferred not to say $=2$. Sixty-three had heterosexual orientation, 5 bisexual, 9 homosexual, and 1 did not say. We also checked that participants had not been directly exposed to terrorism (see results section).

Out of the 86 participants, four showed inconsistent preferences, for two participants, data on economic 


\section{Journal of Terrorism Research}

preferences were missing, two did not complete the writing task, so their data were removed from the analysis. The remaining complete questionnaires for seventy-eight_participants (39 males, 35 females, 4 preferred not to declare; mean age 32 years) were analysed.

\section{Design}

A between-subjects design was used.

Threat manipulation. Priming in the TMT protocol allows some flexibility (see review by Burke et al., 2010). Most popular prime involves asking participants to write down what they think happens when they die, and to jot down emotions aroused by thoughts of their own death. Some primes used death-related pictures; there have also been successful primes using terrorism-related stimuli (Echebarria Echabe \& Perez, 2015). The goal of this study was to prime Terrorism as it is naturally encountered through the media; priming Mortality in the same format would enable comparisons between combination of MS and uncertainty in case of Terrorism.

Terrorism prime comprised extracts from a video: 'Dozens Killed in Islamic Militant Attacks in Four Countries' ( 2 min 50s; Bloomberg Business, 2015). The video emphasized high uncertainty and unpredictability of the threat, discussed whether the attacks were to increase in frequency, and whether danger might come from extremist citizens within western countries; it did not contain explicitly aversive images (see Supplementary Material 2.4 for script and screenshots). Mortality prime posed a challenge of finding an applicable TV-programme; our best option comprised extracts from the video: 'How Much Is Your Dead Body Worth' (2 min 33s; BBC Horizon, 2008). The control video was 'The Truth About...Your Teeth' (2 min 0s; BBC One, 2015). Dental pain has been widely used as control prime and can produce routine levels of anxiety and fear, compared to existential threats (Solomon, Greenberg, \& Pyszczynski, 2004). Following the Threat video, participant completed a task designed to reinforce the prime in the video.

\section{Materials}

RST-PQ. The 65 items Reinforcement Sensitivity Theory Personality Questionnaire (RST-PQ, Corr \& Cooper, 2016), consisting of six factors, was used. The behavioural inhibition system (BIS, related to anxiety, responsible for worry, obsessive thoughts and behavioural inhibition) reflects the assessment of goal-conflict, which generates negative emotion and leads to 'cautious approach' (example item, I'm always weighing-up the risk of bad things happening in my life). Distinguishing between the four components of behavioural approach system (BAS) allows finer-grained differentiation of reactions to rewarding stimuli and resulting approach behaviour: BAS Impulsivity (e.g., I'm always buying things on impulse), BAS Goal-Drive Persistence (e.g., I am very persistent in achieving my goals). Items are answered on 4-point Likert scale ranging from 1 (Strongly disagree) to 4 (Strongly agree). The RST-PQ contains two other BAS factors: Reward Interest (e.g., I regularly try new activities just to see if I enjoy them) and Reward Reactivity (e.g., I get a special thrill when I am praised for something I've done well).

Distraction task. According to the TMT literature, the distal, threat-unrelated effects of Mortality threat manifest more strongly after a distraction task, once the threat is out of immediate consciousness (Solomon, Greenberg, \& Pyszczynski, 2004). In compliance with the standard procedures of the field, a self-report mood scale PANAS (Watson, Clark, \& Tellegen, 1988) and general questions supporting cover story were used.

Risk and Delay. This measure was a variation of a standard multiple options checklist widely used in 
experimental literature (Andersen, Harrison, Lau, \& Rutstrom, 2008). For risk, participants answered questions 'What would you prefer to get?' separately for each pair of options: a risky option of ' $50 \%$ chance of $€ 800$ ' and a safe option (ranging over the 11 choices of $€ 100$ to $€ 600$ ). For delay, participants answered the same for each pair of options: a smaller-sooner amount of $€ 100$ "tomorrow" and a larger-later amount (ranging over the 7 choices from $€ 110$ to $€ 170$ ) after a delay of 90 days-this is detailed in Supplementary Material 2.4.

\section{Procedure}

The experiment was based on the Qualtrics Platform. Following an online signature of informed consent, participants completed the RST-PQ personality questionnaire, then were randomly allocated to one of the three Threat conditions. They then proceeded to the distraction task on mood and media preferences, and questions on target economic preferences. The flow of study activities is shown in Figure 1.

\section{Results}

Pearson product-moment correlations and descriptive statistics are shown in Table 1.

\section{Writing Task}

We utilized the writing task with a second purpose of checking participants' self-reported experience with terrorism and identify those who were directly affected.

All the participants under the terrorism treatment completed the writing task (mean length $=43$ words). None of them mentioned direct experience of terrorism. We hoped to see a variety of opinions on terrorism, expected from a sample to be reasonably reflective of a modern Western city. The opinions ranged from radical "Can't wait for a religion free society" to reflective "Complicated. Not black \& white. Don't trust agencies with agendas too much" to analytical "religious fundamentalism is a symptom, not a cause", to detached "Won't be going to Tunisia any time soon", to emotional "I am scared for my family and friends being victims of an attack".

\section{Mood}

We used the PANAS mood scale to compare emotional response to the treatments on the measures of General Positive Affect (GPA, 10 items) and General Negative Affect (GNA, 10 items).

There was no evidence of significant difference in GNA between Mortality and Dentistry, $\mathrm{p}>.10$, which is common for the TMT literature (Lambert et al., 2014 review supporting studies and recent counterevidence). In Terrorism, however, GNA was significantly higher (20.48) compared to Dentistry (16.89), and to Mortality (16.11), $\mathrm{p}<.05$. This suggests that Terrorism evoked proximal (threat-related) emotions, whereas Mortality did not.[3]. 


\section{Journal of Terrorism Research}

\section{Economic Preferences Measures}

\section{Risk-Seeking}

To compare the overall effects of threat manipulation, a between-groups ANOVA was first run with Threat as fixed factor, and Sex, Age and negative Mood as covariates. Three orthogonal contrasts were constructed to assess whether either of two experimental conditions were different from the control condition, and whether the experimental conditions were different between each other. Specifically, we computed a contrast that coded the Terrorism condition as +1 , the Mortality condition as 0 , and the Dentistry condition as -1 , testing whether the Terrorism salience manipulation yielded differential effects on risk-seeking than the control condition. The contrast showed significant differences in mean risk-seeking under Terrorism (4.87) and Dentistry (5.70), $\mathrm{F}(1,78)=5.46, p<.05$. Mean risk-seeking in Terrorism was also significantly lower than in Mortality (5.58), $\mathrm{F}(1,78)=9.81, p<.001$. The same procedure comparing Mortality to control (Terrorism coded as 0 , Mortality as +1 , Dentistry as -1 ) showed no significant difference in means, $p>.10$. This supported our prediction regarding the effects of Terrorism on risk-seeking, but made us weary about the strength of Mortality manipulation.

The prediction about effect of high/low levels of (BAS-related) Impulsivity and (BIS-related) Anxiety on risk preference under threat was tested using the following model.

Risk-seeking $_{\text {scale }}=\alpha+\beta_{0} \operatorname{Mood}_{G N A}+\beta_{1}$ Threat $_{\text {Terr }}+\beta_{2}$ Threat $_{\text {Mort }}+\beta_{3}$ Threat $_{\text {Mort }} \mathrm{x} \mathrm{Mood}_{G N A}+\beta_{4}$ Threat $_{\text {Terr }}$ $\mathrm{x} \mathrm{Mood}_{\text {GNA }}+\beta_{5}$ Personality $_{B A S-I m p}+\beta_{6}$ Personality $_{B I S-A n x}+\beta_{7}$ Threat $_{\text {Terr }} \mathrm{x}$ Personality ${ }_{\text {BAS-Imp }}+\beta_{8}$ Threat $_{\text {Terr }} \mathrm{x}$ Personality $_{\text {BIS-Anx }}+\beta_{9}$ Threat $_{\text {Mort }} \mathrm{x}$ Presonality $_{\text {BAS-Imp }}+\beta_{10}$ Threat $_{\text {Mort }} \mathrm{x}$ Personality ${ }_{\text {BIS-Anx }}+$ Covariates A multivariate ANOVA/GLM was used, with threat as a single fixed factor, and negative Mood, BAS-Imp and BIS-Anxiety as continuous predictor variables. Two-way interactions between Threat and Personality variables, and between Threat and negative Mood, revealed a significant interaction: Threat $x$ BAS- $\operatorname{Imp}, \mathrm{F}(2$, $66)=8.85, p<.001$. A plot of mean Risk-Seeking against Low and High (median-split) BAS-Imp for the three Threat groups in Figure 3 makes it easy to observe that there was no difference under Dentistry; but under Terrorism, individuals high on the BAS-Imp factor showed lower risk-seeking; under Mortality individuals, those high on the BAS-Imp factor tended to show higher risk-seeking.

Formally, the GLM revealed a significant interaction of Terrorism x BAS-Imp, indicating that the effect of BAS-Imp on risk-seeking in Terrorism was significantly lower from that in Dentistry, $\beta$ (diff) $=1.65, p<$ .01 ; however, the evidence only indicated a trending difference in the effect of BAS-Imp on risk-seeking in Mortality, as compared to Dentistry, $p=.16$. The effect of BAS-Imp in Terrorism was also significantly different from that in Mortality, $\beta$ (diff) $=2.78, p<.01$. Following Aiken and West (1991) procedure for decomposing an interaction, the estimated coefficients indicated a significant negative relationship between BAS-Imp and risk-seeking in Terrorism, $\beta=-0.59, \eta^{2}=.11, p<.01$, a significant positive relationship in Mortality, $\beta=0.64, \eta^{2}=.12, p<.01$, but no evidence for an effect in Dentistry, $p>.01$. These results suggest that individuals higher on impulsivity were less risk-seeking under terrorism, which supports our hypothesis. Under mortality prime, individuals higher on impulsivity preferred gambles with higher risk - which is also in line with our hypothesis. This effect, however, was statistically indistinguishable from that in Dentistry condition which requires caution in interpretation.

The model also showed a significant interaction Threat $\mathrm{x}$ BIS-anxiety, $\mathrm{F}(2,66)=3.39, p<.05$, which suggested that the effect in Terrorism was significantly different from that in Mortality, $\beta($ diff $)=1.71, p=.02$; 


\section{Journal of Terrorism Research}

there was no evidence of the effect in Terrorism being different from that in Dentistry, $p>.10$. These results do not support our hypotheses.

\section{Delay}

An ANOVA with Threat as fixed factor, and Sex, Age and negative Mood as covariates, with three orthogonal contrasts to assess overall effect of experimental conditions, showed no difference in mean delay-impatience in three threat groups, $p>.10$. This was anticipated, since in past literature effects were found only when individual differences were considered. The prediction about effect of high/low levels of Impulsivity, Anxiety and BAS-GDP on delay preference under threat was tested using the following model.

Delay-Impatience $_{\text {scale }}=\alpha+\beta_{0} \operatorname{Mood}_{G N A}+\beta_{1}$ Threat $\boldsymbol{\beta}_{2}$ Threat $_{\text {Mort }}+\beta_{3}$ Threat $_{\text {Mort }} \mathrm{x} \mathrm{Mood}_{G N A}+\beta_{4}$ Threat $_{\text {Terr }} \mathrm{x}$ Mood $_{G N A}+\beta_{5}$ Presonality $_{B A S-I m p}+\beta_{6}$ Personality $_{B I S-A n x}+\beta_{6}$ Personality $_{B A S-G D P}+\beta_{8}$ Threat $_{\text {Terr }}$ Personality $_{B A S-}$ ${ }_{I m p}+\beta_{9}$ Threat $_{\text {Terr }} \mathrm{x}$ Personality ${ }_{\text {BIS-Anx }}+\beta_{10}$ Threat $_{\text {Terr }} \mathrm{x}$ Personality ${ }_{B A S-G D P}+\beta_{11}$ Threat $_{\text {Mort }} \mathrm{x}_{\text {Personality }}$ BAS-Imp + $\beta_{12}$ Threat $_{\text {Mort }} \mathrm{x}$ Personality ${ }_{B I S-A n x}+\beta_{13}$ Threat $_{\text {Mort }} \mathrm{x}$ Personality ${ }_{B A S-G D P}+$ Covariates

A multivariate ANOVA/GLM was used, with threat as a single fixed factor, and negative Mood, BAS-Imp, BIS-Anxiety, and BAS-GDP as continuous predictor variables, with two-way interactions between Threat and Personality variables, and between Threat and negative Mood. The model revealed a significant interaction: Mortality x BAS-GDP, $\mathrm{F}(2,63)=4.45, p<.05$. A plot of mean Delay-Impatience against Low and High (median-split) BAS-GDP for the three Threat groups in Figure 4 shows that under Dentistry individuals high on BAS-GDP were more impatient about financial gains than those low; under Terrorism high BAS-GDP individuals tended towards higher impatience; under Mortality, on the contrary, they tended towards lower impatience.

Formally, the effect of BAS-GDP on delay-impatience in Mortality was significantly lower than that in Dentistry, $\beta$ (diff $)=1.31, p<.05$; however, the data did not indicate difference in the effect of BAS-GDP on delay-impatience in Terrorism when compared to Dentistry, $p>.10$. The effect of BAS-GDP on delayimpatience in Mortality was also significantly different from that in Terrorism, $\beta($ diff $)=1.64, p<.01$. Following Aiken and West (1991), the estimated coefficients indicated a significant negative effect of BASGDP on delay-impatience in Mortality, $\beta=-0.36, \eta^{2}=.06, p<.05$, a trending positive effect in Terrorism, $\beta=$ $0.40, \eta^{2}=.05, p<.10$, but no effect in Dentistry, $p>.10[4]$. This evidence supported the hypothesis that lower goal drive-persistence would heighten delay-impatience under Mortality. The data also suggested possibility of an opposite effect of BAS-GDP in Terrorism, which was not anticipated in the hypotheses.

The model also revealed a significant interaction Terrorism $x$ BIS-anxiety, indicating that the effect of BISanxiety on delay-impatience in Terrorism was significantly higher than that in Dentistry, $\beta($ diff $)=1.28, p<$ .05 ; there was a trending difference in the effect of BIS-anxiety on delay-impatience in Mortality as compared to Dentistry, $p<.10$. The effect of BIS-anxiety on delay-impatience in Terrorism was also significantly different from that in Mortality, $\beta($ diff $)=1.68, p<.01[5]$. These results suggest that individuals higher on anxiety were generally less impatient about delayed rewards, and there was a change in this preference under threat - which is an interesting evidence, but we do not consider it strong enough to support our hypotheses. There were no effects of BAS-Imp on delay-impatience in the data. The model with full set of covariates also revealed an overall negative effect of BAS-RI on delay-impatience, $\beta=-0.34, \eta^{2}=.12, p=.01$.

There was clear evidence of participants higher on Impulsivity becoming less risk-seeking under Terrorism (displayed in Figure 3.B) and for participants lower on BAS-GDP becoming more delay-impatient under 


\section{Journal of Terrorism Research}

Mortality (displayed in Figure 4.B). The effects of BIS-anxiety were less pronounced and mixed.

Comparing with past literature, Griskevicius et al. (2011) found similar size effects on risk-seeking under stimuli of life-threatening and treacherous future: when moderating role of socio-economic status at childhood (SES) was considered; the effects similarly divided into lower risk-seeking for higher SES $\left(\eta^{2}=.10\right)$ and higher risk-seeking for lower SES $\left(\eta^{2}=.14\right)$. The effects delay-impatience choices were similarly smaller $\left(\eta^{2}=.08, \eta^{2}=.12\right)$, some of them of marginal significance. Yavuz and Van den Bos (2009) reported larger effects of mortality $\left(\eta^{2}=.20\right)$ and uncertainty $\left(\eta^{2}=.46\right)$ on the negative reaction towards an essay violating the cultural worldviews, which suggests that effects in the domain of economic preferences may be smaller than in domain of emotional judgments and cultural beliefs.

\section{General Discussion}

If you take a group of people who are similarly aware of the existence of terrorism threat in their life, and expose them to a media reminder of it, would this lead to change in their decision-making? If this is found then are there personality differences which predict these psychological reactions? Our study set out to answer these questions. Our results show that for impulsive individuals, exposure to media reminders of terrorism systematically increase their aversion to financial risk - compared to being exposed to routine life nuisances such as dental procedures. Becoming more conservative in risk-taking decisions can have strong effects on one's life; for instance, this could translate into missed life opportunities (e.g., changing jobs, pursuing new projects, and starting a family) when contact with the media (including social type) is extensive. Therefore, impulsivity influences not just attitude towards risk, but also behaviour.

To what extent it is rational to adjust decision-making in view of terrorism as a low probability but, potentially, high-impact, threat is still a matter of debate. The modern world, however, can be particularly anxiety provoking - great technical progress in the development of media also means that individuals with a pessimistic outlook on the world can 'feed' this worldview by selectively accessing negative news from around the world. The tendency of social media to show users 'more of a like' can create skewed impressions of the world. It is important that individuals are aware of susceptibility of their personality to such effects and do not let such effects prevent them from pursuing their goals and making well-weighted decisions.

In terms of limitations of our research, future work with larger sample sizes are needed to replicate and extend our findings. In addition, we measured only the immediate effect on economic preferences, so we cannot say anything about longer terms effects.

\section{Conclusion}

Understanding the mechanisms through which anxiety caused by news of terrorist attacks can affect economic preferences in daily life through perceived threat and uncertainty can help us not allow such news to distract us from important goals in our life - informing more objective decision-making on individual level, and relevant policy-making on country level. The way individuals perceive terrorism threat can result in changes of risk-taking and delay-discounting choices, and basic approach-avoidance personality factors shows that some people may be especially vulnerable to these effects. It is important to understand and anticipate citizens' reactions to terrorism as a threat to their usual way of life to mitigate negative impact. It is to be hoped that the findings we report serve to shed light on the important impact on key economic variables as well as the influence of personality factors in shaping these psychological reactions. 


\section{Journal of Terrorism Research}

\section{Acknowledgements}

We are grateful to Arnaud Wisman, Rotem Perach, and Peter Sozou for the insightful feedback on an earlier draft of this manuscript.

\section{References}

Aiken, L. S., \& West, S. G. (1991). Multiple regression: Testing and interpreting interactions. Newbury Park, CA: SAGE Publications.

Almlund, M., Duckworth, A. L., Heckman, J. J., \& Kautz, T. D. (2011). Personality psychology and economics (No. w16822). National Bureau of Economic Research. doi:10.1016/B978-0-444-53444-6.00001-8

Andersen, S., Harrison, G. W., Lau, M. I., \& Rutstrom, E. E. (2008). Eliciting risk and time preferences. Econometrica, 76(3), 583-618. doi:10.1111/j.1468-0262.2008.00848.x

Ben-Zur, H., \& Zeidner, M. (2009). Threat to life and risk-taking behaviors: A review of empirical findings and explanatory models. Personality and Social Psychology Review, 13(2), 109-128. doi: $10.1177 / 1088868308330104$

Ben-Zur, H., Gil, S., \& Shamshins, Y. (2012). The relationship between exposure to terror through the media, coping strategies and resources, and distress and secondary traumatization. International Journal of Stress Management, 19(2), 132-150. doi:10.1037/a0027864

Burke, B. L., Martens, A., \& Faucher, E. H. (2010). Two decades of terror management theory: A metaanalysis of mortality salience research. Personality and Social Psychology Review, 14(2), 155-195. doi: $10.1177 / 1088868309352321$

Corr, P. J. (2013). Approach and avoidance behaviour: Multiple systems and their interactions. Emotion Review, 5, 285-290. doi:10.1177/1754073913477507

Corr, P. J., \& Cooper, A. J. (2016). The Reinforcement Sensitivity Theory of Personality Questionnaire (RSTPQ): Development and validation. Psychological assessment, 28(11), 1427-1440. doi:10.1037/pas0000273

Costa, P. T., \& MacCrae, R. R. (1992). Revised NEO personality inventory (NEO PI-R) and NEO fivefactor inventory (NEO-FFI): Professional manual. Psychological Assessment Resources, Incorporated. doi:10.1037//1040-3590.4.1.5

Echebarria Echabe, A., \& Perez, S. (2015). The impact of different procedures to arouse mortality awareness on various worldview dimensions. European Journal of Social Psychology, 46, 392-399. doi:10.1002/ejsp.2144.

Gigerenzer, G. (2006). Out of the frying pan into the fire: Behavioral reactions to terrorist attacks. Risk Analysis: An Official Publication of the Society for Risk Analysis, 26(2), 347-51. Doi:10.1111/j.15396924.2006.00753.x

Gray, J. A., \& McNaughton, N. (2000). The neuropsychology of anxiety: An enquiry into the function of the septo-hippocampal system. Oxford: Oxford University press

Griskevicius, V., Tybur, J. M., Delton, A. W., \& Robertson, T. E. (2011). The influence of mortality and socioeconomic status on risk and delayed rewards: A life history theory approach. Journal of Personality and Social Psychology, 100(6), 1015-1026. Doi:10.1037/a0022403

Hirsh, J. B., \& Inzlicht, M. (2008). The devil you know: Neuroticism predicts neural response to uncertainty. Psychological Science, 19(10), 962-967. doi:10.1111/j.1467-9280.2008.02183.x 


\section{Journal of Terrorism Research}

Lambert, A. J., Eadeh, F. R., Peak, S. a, Scherer, L. D., Schott, J. P., \& Slochower, J. M. (2014). Toward a greater understanding of the emotional dynamics of the mortality salience manipulation: Revisiting the "affectfree" claim of terror management research. Journal of Personality and Social Psychology, 106(5), 655-78. doi: $10.1037 / \mathrm{a} 0036353$

Lauriola, M., \& Levin, I. P. (2001). Personality traits and risky decision-making in a controlled experimental task: An exploratory study. Personality and Individual Differences, 31(2), 215-226. doi:10.1016/S01918869(00)00130-6

Maguen, S., Papa, A., \& Litz, B. T. (2008). Coping with the threat of terrorism: A review. Anxiety, Stress, and Coping, 21(1), 15-35. doi:10.1080/10615800701652777

McNaughton, N., \& Corr, P. J. (2004). A two-dimensional neuropsychology of defense: Fear/anxiety and defensive distance. Neuroscience and Biobehavioral Reviews, 28, 285-305. doi:10.1016/j.neubiorev.2004.03.005 Nicholson, N., Soane, E., Fenton-O'Creevy, M., \& Willman, P. (2005). Personality and domain-specific risk taking. Journal of Risk Research, 8(2), 157-176. doi:10.1080/1366987032000123856

Paulus, M. P., Rogalsky, C., Simmons, A., Feinstein, J. S., \& Stein, M. B. (2003). Increased activation in the right insula during risk-taking decision making is related to harm avoidance and neuroticism. NeuroImage, 19(4), 1439-1448. doi:10.1016/S1053-8119(03)00251-9

Pavia, T. M., \& Mason, M. J. (2004). The reflexive relationship between consumer behavior and adaptive coping. Journal of Consumer Research, 31(2), 441-454. doi:10.1086/422121

Slovic, P. (2002). Terrorism as hazard: A new species of trouble. Risk Analysis, 22(3), 425-426. doi: $10.1111 / 0272-4332.00053$

Solomon, S., Greenberg, J., \& Pyszczynski, T. (2004). The cultural animal: Twenty years of terror management theory and research. In Handbook of Experimental Existential Psychology (pp. 13 -34). New York, NY: Guilford.

Sunstein, C. R. (2003). Terrorism and probability neglect. Journal of Risk and Uncertainty, 26(2-3), 121-136. doi:10.1023/A:1024111006336

Van den Bos, K., Poortvliet, P. M., Maas, M., Miedema, J., \& van den Ham, E. J. (2005). An enquiry concerning the principles of cultural norms and values: The impact of uncertainty and mortality salience on reactions to violations and bolstering of cultural worldviews. Journal of Experimental Social Psychology, 41(2), 91-113. doi:10.1016/j.jesp.2004.06.001

Watson, D., Clark, L. a, \& Tellegen, A. (1988). Development and validation of brief measures of positive and negative affect: the PANAS scales. Journal of Personality and Social Psychology, 54(6), 1063-70. doi:10.1037/0022-3514.54.6.1063

Yavuz, H., \& Van den Bos, K. (2009). Effects of uncertainty and mortality salience on worldview defense reactions in Turkey. Social Justice Research, 22(4), 384-398. doi:10.1007/s11211-009-0104-5

Zuckerman, M., \& Kuhlman, D. M. (2000). Personality and risk-taking: Common biosocial factors. Journal of Personality, 68(6), 999. doi:10.1111/1467-6494.00124

\section{Web References}

BBC Horizon. (2008). How much is your dead body worth? [Video webcast]. Retrieved September 16, 2015, 


\section{Journal of Terrorism Research}

from http://www.bbc.co.uk/sn/tvradio/programmes/horizon/broadband/tx/bodyparts/

BBC One. (2015). The truth about...your teeth [Video webcast]. Retrieved September 16, 2015, from http:// www.bbc.co.uk/programmes/b05y3953

Bloomberg Business. (2015). Dozens Killed in Islamic Militant Attacks in Four Countries-[Video webcast]. Retrieved September 16, 2015, from http://www.bloomberg.com/news/articles/2015-06-26/dozens-killedfrom-tunisia-to-france-on-caliphate-anniversary

Watchwellcast. (2013). 5 Tricks for overcoming fear [Video webcast]. Retrieved September 16, 2015, from https://www.youtube.com/watch?v=GDjwfF

\section{Notes}

[1] The main article and supplementary materials contain all measures, manipulations, and exclusions in the study.

[2] four missing values.

[3] Full analysis in Supplementary Material 2.3.

[4] Full GLM table in Supplementary Material 2.1

[5] Full GLM table in Supplementary Material 2.1

\section{About the authors}

Alina Velias is a PhD student at the Economics department at City, University of London. She holds an MSc in Behavioural Economics, which she pursued after graduating with BSc Philosophy and Economics from the London School of Economics (LSE) and several years of working in the private sector. Her research to date has been focusing on experimental investigation of role of psychological traits in economic decision making. Her broader interests include applications of behavioural economics for industry and policy-making.

Philip Corr is a Professor of Psychology at City University London, UK. Previously, he was a Professor of Psychology at Swansea University, and then University of East Anglia. Corr has published over 100 scientific papers, and he is the author of 'Understanding Biological Psychology' (2006; Oxford: Blackwell); the single editor of 'The Reinforcement Sensitivity Theory of Personality' (2008; Cambridge University Press); and the joint editor (with Gerald Matthews) of 'The Cambridge Handbook of Personality Psychology' (2009; Cambridge University Press).

Professor Corr is one of the Co-Founding Presidents (along with Professor Eammon Ferguson, Nottingham University) of the British Society for the Psychology of Individual Differences (BSPID), which has the aim of furthering the scientific study of individual differences in the UK. 